\title{
Experience with the reinforcer and the preference for earned rather than free reinforcers in rats
}

\author{
CURTIS W. CARLSON and DAVID C. RICCIO \\ Kent State University, Kent, Ohio 44242
}

\begin{abstract}
Manipulating experience with the reinforcer, through either home cage presentations of Noyes pellets or availability of the free reinforcer immediately prior to testing, attenuated the preference for earned as opposed to free reinforcers. Similarly, changing the reinforcer to one of a different flavor at testing increased the preference for the noncontingent reinforcer. These results are consistent with an interpretation of earned reinforcer preference which emphasizes the role of the reinforcer as a discriminative signal for further instrumental responding. It is suggested that the tendency to perform instrumental responses for reinforcers when free reinforcers are available can be explained in terms of traditional learning processes.
\end{abstract}

Studies have shown that animals will make instrumental responses to obtain a food (or water) reinforcer even when it is freely available (Carder \& Berkowitz, 1970; Jensen, 1963; Singh, 1970; Tarte \& Snyder, 1973). Since the preference for earned reinforcers reflects unnecessary expenditure of effort, it has been argued that the phenomenon cannot be explained in terms of traditional learning and motivational processes (Neuringer, 1969; Singh, 1970). Before this position is accepted, however, further examination of the possible contribution of traditional learning mechanisms in accounting for the preference for earned reinforcers seems warranted. Reid (1957) and Rescorla and Skucy (1969) have shown that delivery of noncontingent reinforcers during extinction sessions retards the weakening of instrumental responding. They suggested that the response maintenance was due in part to learned stimulus characteristics of the reinforcer. Denny (1971) has also considered the possibility that the reinforcer is a potential stimulus for instrumental responding. These findings suggest that the preference for earned rather than free reinforcers might also be explained in terms of the stimulus characteristics of the reinforcers. In three experiments, we examined the possibility that during training the reinforcer becomes a discriminative stimulus for the instrumental response which produces it, and subsequently maintains responding in the presence of noncontingent reinforcers.

This paper is based on a thesis submitted by the first author to Kent State University in partial fulfillment of the requirements for the MA degree. This research was supported in part by NSF Grant GB 41488 to the second author. We thank Drs. J. S. Myer, F. R. Treichler, and R. M. Vardaris for helpful suggestions. Requests for reprints should be sent to Curtis W. Carlson, Department of Psychology, Kent State University, Kent, Ohio 44242.

\section{EXPERIMENT I}

If a reinforcer serves as a discriminative stimulus for responding, manipulations that increase experience with the reinforcer outside the instrumental situation should reduce this feature of contingent reinforcers and lead to increased choice of noncontingent reinforcers. Experiment 1 was designed to test this prediction by presenting food pellets to subjects in their home cages prior to and during days of experimental sessions.

\section{Method}

Subjects. Thirty-six adult male albino rats, purchased from Holtzman Co., Madison, Wisconsin, were maintained in individual $24.1 \times 17.8 \times 17.8 \mathrm{~cm}$ cages for at least 10 days prior to the beginning of the experiment. Purina Laboratory Chow and water were available ad lib. Preexperimental weights of the rats ranged from 348 to $484 \mathrm{~g}$.

Apparatus. Three identical $25.4 \times 20.5 \times 20.5 \mathrm{~cm}$ chambers. constructed of clear acrylic sheets, were employed. Each chamber was placed upon a grid floor, composed of stainless steel grids positioned $1.0 \mathrm{~cm}$ apart, and was fitted with a Scientific Prototype lever located $3.8 \mathrm{~cm}$ above the grid floor and $3.7 \mathrm{~cm}$ from the right wall. Noyes $45-\mathrm{mg}$ food pellets were dispensed into a foodcup, placed $3.7 \mathrm{~cm}$ to the left of the lever, and a $6.0 \times 3.2 \times 3.0 \mathrm{~cm}$ rectangular plastic container was centrally located on the wall opposite the lever, resting upon the grid floor. The experimental chamber and grid floor assembly were placed within a $72.4 \times 72.4 \times 38.1 \mathrm{~cm}$ wooden container fitted with an exhaust fan which circulated air and provided masking noise. A $25.4 \times 12.7 \mathrm{~cm}$ acrylic-covered window permitted observation of the subjects during the experimental sessions. Illumination was provided by a 7.5 -W bulb located on an inside wall of the wooden container. Responding and reinforcer presentations were recorded and controlled by standard electromechanical equipment.

Procedure. The subjects were quasi-randomly assigned to four groups of nine each and reduced through restricted feeding to $80 \%$ ad-lib weight. All subjects were maintained at that level for 10 days (Days 1-10), after which they received one session of barpress training (Day 11), followed by nine daily $1 / 2-h$ sessions (Days 12-20) of barpressing on a schedule of continuous 
Table 1

Median proportions of pellets earned by various treatment groups.

\begin{tabular}{lccc}
\hline & \multicolumn{3}{c}{ Test Session (Day) } \\
\cline { 2 - 4 } Group & 21 & 22 & 23 \\
\hline & \multicolumn{3}{c}{ Experiment I } \\
B & .883 & .940 & .939 \\
C & .694 & .811 & .811 \\
P & .734 & .796 & .809 \\
C/P & .712 & .677 & .695 \\
& & Experiment II & \\
B & - & .940 & .939 \\
BL & - & .628 & .745 \\
& & Experiment III & \\
B & .883 & .940 & .939 \\
S-F & .714 & .836 & .826 \\
F-S & .394 & .296 & .526 \\
\hline
\end{tabular}

reinforcement (CRF). Three daly $1 / 2-h$ test sessions followed (Days 21-23), in which 300 Noyes food pellets were available in the free-food container.

Subjects in the concurrent reinforcer group (Group C) received 30 pellets per day in their home cages on Days 11-20. Prior reintorcer group (Group P) subjects received 30 pellets per clay in their home cages on Days 1-10. Subjects in the concurrent/ prior reinforcer group (Group $C / P$ ) received 30 pellets per day in their home cages ol Day, 1-20. Bisselme reinforcer group (Group B) subjects recelved no Noyes pellets prior to testing other than those ubtamed through instrumental responding. The proportion of pellets earned during each test session was the dependent measule in this and the subsequent two experiments.

\section{Results}

The median proportions of pellets earned by the treatment groups are depicted in Table 1. Two-tailed, nonparametric tests were used for all analyses. A Kruskal-Wallis one-way analysis of variance indicated that overall differences between groups were significant on Day $21[\mathrm{H}(3)=8.25, \mathrm{p}<.05]$, but not on Day $22[\mathrm{H}(3)=4.71$, n.s. $]$ or Day $23[\mathrm{H}(3)=$ 4.47 , n.s.]. Subsequent Mann-Whitney $U$ tests revealed significant differences between Group B and all other groups on Day 21 [B vs. C: $U(9,9)=17$, $\mathrm{p}=.05$; B vs. $\mathrm{P}: \mathrm{U}(9,9)=12, \mathrm{p}<.02$; B vs. C $/ \mathrm{P}$ : $U(9,9)=15, p<.05]$. Friedman two-way analyses of variance indicated no significant within-group sessions effects $\left[\mathrm{B}: \chi_{\mathrm{r}}^{2}(3 / 9)=2.78\right.$, n.s.; $\mathrm{C}$ : $\chi_{\mathrm{r}}^{2}(3 / 9)=0.56$, n.s.; P: $\chi_{\mathrm{r}}^{2}(3 / 9)=4.11$, n.s.; C/P: $\chi_{\mathrm{I}}^{2}(3 / 9)=2.56$, n.s.].

\section{Discussion}

These initial results show that experience with the reinforcing food pellets outside the instrumental situation decreases preference for earned reinforcers. The persistence of the effects of this experience is reflected in the apparent lack of difference between Group $P$, which received free pellets prior to instrumental sessions, and Group $C$, which received free pellets concurrent with instrumental sessions. Furthermore, the lack of difference between Group C/P, which received 600 noncontingent Noyes pellets (Days 1-20), and Groups $C$ and $P$, which recelved only 300 noncontingent reinforcers (Days 11-20 and 1-10, respectively), would seem to indicate either that the experiential effects of noncontingent reinforcers quickly reach asymptotic levels or that a larger difference in the amount of experience with the noncontingent reinforcer is necessary to distinguish between these groups. While these results do not allow the ordering of Treatment Groups $\mathrm{C}, \mathrm{P}$, and $\mathrm{C} / \mathrm{P}$ on the basis of amount and recency of noncontingent pellets received on Days 1-20, the expected reduction in instrumental responding relative to Group B was obtained. The lack of the expected within-group sessions effects from free-food consumption during test sessions appears to be a result of the extensive number of CRF sessions. Another study, using fewer CRF training sessions (Knutson \& Carlson, 1973), obtained the expected decrease in earned food consumption over test sessions. The loss of significant differences between groups on Days 22 and 23 may be attributable to differential free-food consumption during test sessions by individual subjects within each group, leading to increased variability.

\section{EXPERIMENT II}

If experience with the reinforcer outside of the instrumental situation decreases preference for earned reinforcers, then allowing the subjects to consume free pellets in the experimental chamber prior to testing should also reduce preference for earned reinforcers.

\section{Method}

Subjects. Nine adult male albino rats were obtained and housed in the same manner as in Experiment 1. Preexperimental weights ranged from 411 to $453 \mathrm{~g}$.

Apparatus. The apparatus used was identical to that used in Experiment I, with the addition of a sheet of clear acrylic which could be positioned immediately in front of the lever and foodcup.

Procedure. The nine subjects constituted the blocked group (Group BL), and were treated in a manner identical to Group B of Experiment 1 on Days 1-20. On Day 21, with free pellets available, the subjects in Group BL were placed in the chamber in the usual manner, except for the acrylic sheet, which precluded access to the lever and foodcup. This blocking procedure was in effect for the first $10 \mathrm{~min}$ on Day 21 . Following this period, the free-food cup was refilled with 300 pellets, and the acrylic sheet removed. The session then continued for $30 \mathrm{~min}$. The test sessions on Days 22 and 23 were the same as those employed with Group B, the group with which Group BL was compared. Group B was run concurrently with all experimental groups, and thus provides the baseline for each experiment presented in this report.

\section{Results}

The median proportions of pellets earned by these 
groups are shown in Table 1. A significant difference between Group B and Group BL was found on Day $22[\mathrm{U}(9 / 9)=14, \mathrm{p}=.02]$ but not on Day 23 $[\mathrm{U}(9 / 9)=20$, n.s. $]$. Again, no within-group sessions effects were significant [B: $\chi_{r}^{2}(3 / 9)=2.78$, n.s.; BL: $\chi_{\mathrm{r}}^{2}(3 / 9)=2.78$, n.s..

\section{Discussion}

Allowing the subjects to consume free pellets prior to testing attenuates the preference for earned food, an outcome which is consistent with the results of the previous experiment. One limitation of our design is the absence of a blocked group that does not have free pellets available. Such a blocking control group was considered unnecessary given that the purpose of the blocking manipulation was to encourage the consumption of pellets prior to testing. Furthermore, Experiments I and III provide relatively direct evidence of the role of reinforcer experience in controlling instrumental responding when free food is available. Thus it seems reasonable to assume that the reduction in earned pellets in Experiment II is related to the consumption of food during blocking, and not to blocking per se. It appears that a range of experiences with the reinforcing pellets outside of the instrumental situation can decrease the preference for earned food during test sessions.

\section{EXPERIMENT III}

According to our analysis, changing a distinctive feature of the reinforcers at testing should also reduce the preference for the earned reinforcers. In the final experiment, this operation was examined using food and sucrose pellets.

\footnotetext{
Method

Subjects. Fourteen adult male albino rats, obtained and mainlained in the same manner as those in the previous two experiments, served as subjects in this experiment. Preexperimental weights ranged from 370 to $454 \mathrm{~g}$.

Apparatus. The apparatus was the same as that used previously.

Procedure. The 14 subjects were divided into two groups of seven and treated like those subjects in Group B with the exception of reinforcer type. Group F-S was trained on standard Noyes food pellets, and tested on Noyes sucrose pellets, while the subjects in Group S-F were treated in the opposite manner. Subjects in Group B were, of course, trained on food pellets and tested on food pellets. For all groups, the pellets in the dispenser were the same as those in the free-food container.
}

\section{Results}

Again, the group medians are presented in Table 1. Overall group differences were significant on all three test days [Day 21: $H(2)=13.23, p<.01$; Day 22: $H(2)=6.92, p<.05 ;$ Day 23: $H(2)=9.80$, $\mathrm{p}<.011$. Subsequent tests showed that all differences between groups were significant on Day 21 (B vs. S-F: $\mathrm{U}(9 / 7)=10, \mathrm{p}<.05 ; \mathrm{B}$ vs. F-S: $\mathrm{U}(9 / 7)=2$, $\mathrm{p}<.002$; S-F vs. F-S: $U(7 / 7)=11, \mathrm{p}<.05$ ], but only the difference between Group B and Group F-S was significant on Days $22[U(9 / 7)=12, p=.05]$ and $23[U(9 / 7)=6, p<.02]$. Again, group sessions effects were not significant $\left(B: \chi_{r}^{2}=2.78\right.$, n.s.; $S-F: \chi_{r}^{2}=0.08$, n.s.; F-S: $\chi_{\mathrm{r}}^{2}=0.94$, n.s.).

\section{Discussion}

This last experiment shows that changing the reinforcer in a distinctive manner prior to testing attenuates the preference for earned food. The fact that both Group F-S and Group S-F show less preference for earned reinforcers than Group B indicates that the reinforcers are exerting some stimulus control over the behavior of the subjects. Clearly, a preference for sucrose within each group would not be a consideration, since the same reinforcer was present in both the pellet dispenser and the free-food container at testing. Differences between Groups F-S and S-F may be attributable to a preference for sucrose, but lacking a Group S-S, a definitive statement cannot be made concerning the absolute effects of preferred substances on the persistence of responding when food is freely available. Nevertheless a change in the features of the pellets decreases responding for earned food, regardless of food preferences.

\section{GENERAL DISCUSSION}

These data are consistent with the view that preference for earned food is affected by the reinforcer serving as a discriminative stimulus for the response that produced it. It might be argued that the noncontingent pellet presentations would result in different drive levels between the experimental and baseline groups, but the 30 Noyes pellets would appear to represent a negligible increment to the subject's daily intake. More importantly, daily rations of Purina Chow were adjusted in an attempt to maintain all rats at a relatively constant degree of deprivation ( $80 \%$ of ad-lib weight). Thus, it seems unlikely that the present results could be attributed to differences in drive level.

This view of the reinforcer as a discriminative stimulus may explain why some investigators (Carder, 1972; Taylor, 1972) have not demonstrated preference for the earned reinforcer when the reinforcer was water. The standard presentation of water via drinking tubes for the maintenance of rats in home cages might make water as a reinforcer a less effective discriminative stimulus for instrumental responding because of the inherent extensive past experience with the to-be-used reinforcer.

Some studies, using long sessions of free food consumption (Hothersall, Huey, \& Thatcher, 1973; Tarte, Townsend, \& Vernon, 1973), have not found a preference for earned food. Such results provide additional, albeit indirect, evidence for the effects of noncontingent reinforcer experience on the prefer- 
ence for response-contingent reinforcers.

Container neophobia has recently been advanced as an explanation for the preference for responsecontingent reinforcers (Mitchell, Scott, \& Williams, 1973). The procedures used in the study of Mitchell et al., however, confound container neophobia and prior experience with the noncontingent reinforcer. In our three experiments, the free-food containers were present at all times in the experimental chambers. Thus, visual and olfactory cues should have been familiar to all subjects, and if there were any container neophobia it should have been equal for all of them. Container neophobia does not therefore appear to be an adequate alterrative explanation for the preference for responsecontingent reinforcers.

Recently, two studies have suggested that stimulus change, either in reinforcement schedule (Taylor, 1975) or in external feedback stimuli (Wallace, Osborne, Norborg, \& Fantino, 1973), may be used to explain persistence of responding when food is freely available. While similar in theme, both of these investigations required changes in the test situation with respect to instrumental responding. The results of our three experiments suggest that the reinforcer itself serves to maintain instrumental responding. Our first two experiments used no change at testing other than the presence of the free reinforcers, yet group differences were obtained. While the manipulations clearly did not eliminate the preference for earned reinforcers, perhaps it is more surprising that a mere 30 pellets per day would attenuate the robust preference for earned reinforcers. These findings suggest that the reinforcer serves as a potent discriminative stimulus under baseline conditions.

The present interpretation suggests that a common basis may be responsible for the usual preference for earned over freely available reinforcers in a choice situation (e.g., Group B here), and the effects of noncontingent reinforcers upon a previously trained operant response either in extinction (Boakes, 1973; Rescorla \& Skucy, 1969) or in a responsecontingent schedule of reinforcement (Boakes, Halliday, \& Poli, 1975; Zamble, 1972). For example, Hoakes (1973), using pigeons, found that response rates decreased less rapidly in extinction when response-independent reinforcers were presented, a result in agreement with the findings of Rescorla and Skucy (1969), who used rats as subjects. If our interpretation of these phenomena is correct, then the effects of manipulations of prior reinforcer history upon responding maintained in extinction through noncontingent reinforcer presentations would be of interest. For example, the delivery of free but novel food reinforcers during extinction should be less effective than noncontingent presentations of the original training reinforcer in maintaining instrumental responding.
By way of summary, the major import of this paper lies in demonstrating that the preference for earned reinforcers, rather than representing a unique learning phenomenon, may be governed by traditional learning processes. The preference for earned as opposed to freely available reinforcers appears to be related to the food pellets serving as stimuli for continued responding.

\section{REFERENCES}

BoAkEs, R, A. Response decrements produced by extinction and by response-independent reinforcement. Journal of the Experinental A nulysis of Behavior, 1973, 19, 293-302.

Boakes, R. A., Halliday, M. S.. \& Poli, M. Response additivity: Effects of superimposed free reinforcement on a variable-interval baseline. Journal of the Experimental Analysis of Behavior, 1975, 23, 177-191.

Carder, B. Rats' preference for earned in comparison with free liquid reintorcers. Psychonomic Science, 1972, 26. 25-26.

Carder, B., \& Berkowitz, K. Rats' preference for earned in comparison with tree food. Sctence, 1970, 167. 1273-1274.

DENNY. M. R. A theory of experimental extinction and its relation to a general theory. In H. H. Kendler \& J. T. Spence (Eds.). Essays in neobehavionism: A memorial volume to Kenneth W. Spence. New York: Appleton-Century-Crofts, 1971.

Hothersall, D., Huey. D., \& Thatcher, K. The preference of rats for free or response-produced food. Animal Leaming \& Behavior. 1973, 1. 241-243.

Jensen, G. D. Preference for bar pressing over "freeloading" as a function of number of rewarded presses. Joumal of Experimental Psychology. 1963, 65, 451-454.

Knutson, J. F.. \& Carlson, C. W. Operant responding with free access to the reinforcer: $A$ replication and extension. Animal Learning \& Behavior, 1973, 1. 133-136.

Mitchell, D., Scott. D. W.. \& Williams, K. D. Container ncophobia and the preference for earned fond. Behavioral Biology, 1973, 9. 613-624.

Neuringer, A. J. Animals respond for food in the presence of free tood. Science, 1969, 166, 399-401.

REID. R. L. The role of the reinforcer as a stimulus. British Journal of Psychology, 1957, 49, 202-209.

Rescorla, R. A., \& SkUCY, J. C. Effect of response-independent reinforcers during extinction. Journal of Comparative and Physological Psychology, 1969. 67. 381-389.

Singh. D. Preference for bar pressing to obtain reward over freeloading in rats and children. Journal of Comparative and Phvsiological Psychology, 1970, 73, 320-327.

TARTE, R. D., \& SNYDER, R. L. Some sources of variation in the bar-pressing versus freeloading phenomenon in rats. Journal Comparative and Physiological Psychology. 1973, 84. 128-133.

Tarte, R. D., Townsend, S. G., \& Vernon, C. R. Housing environments and the barpressing vs. freeloading phenomenon in rats. Bulletin of the Psychonomic Society, 1973. 2, 69-71.

TAYLOR. G. T. A limitation of the contrafreeloading phenomenon. Psychonomic Science, 1972, 29. 173-174.

TAYlor, G. T. Discriminability and the contrafrecloading phenomenon. Journal of Comparative and Physiological Psychology, 1975, 88, 104-109.

Wallace, F. R., Osborne, S., Norborg, J., \& Fantino, E. Stimulus change contemporaneous with food presentation maintains responding in the presence of free food. Science, 1973, 182, 1038-1039.

Zamble, E. A "freeloading" effect: Changes in response rate following non-contingent food reward. Canadian Journal of Psychology, 1972. 26. 336-347.

(Recelved for publication September 8, 1975: revision accepted December 8,1975 .) 